\title{
Plecopteren aus der Umgegend von Brandenburg.
}

\section{Von Dr. E. Schoenemund, Werden (Ruhr).}

Auf einer fischereibiologischen Exkursion, die ich mit Dr. Mertens-Friedrichshagen am 12. Mai 1921 an der Plane, einem Zuflufs der Havel, unternahm, hielt ich auch Umschau nach Plecopteren. Meine Vermutung, in dem flachen Sandgebiet bei Brandenburg eine ganz andere Fauna anzutreffen als in den bisher von mir untersuchten Gebirgsgegenden Rheinlands und Westfalens, fand ich durch Funde bestätigt. Obgleich ich nur an einem Vormittag die Neue Plane bei Reckahn auf einer Länge von etwa $200 \mathrm{~m}$ absuchen konnte, fand ich dort nicht weniger als 8 Arten vor. Es sind:

1. Perla vitripennis Burm. Diese Art ist bisher in den gebirgigen Gegenden. Westdeutschlands nicht gefunden worden. Ihr Vorkommen scheint also mehr auf die Ebene beschränkt zu sein. Die Flugzeit liegt im Juni, ich erbeutete deshalb lediglich einige Larven. Dr. Mertens ermöglichte aber in den grofsen Aquarien der Landesanstalt für Fischerei zu Friedrichshagen die Aufzucht der gegen Wasserwechsel sehr empfindlichen Perla-Larven und erhielt $2 \sigma^{7} \sigma^{7}$ und 1 q. Die Larven besitzen eine prächtige Rückenund Kopfzeichnung, wodurch sie sich von den anderen Vertretern der Gattung sofort unterscheiden lassen. Dá ich mittlerweile auch von allen übrigen bekannten deutschen Perla-Arten die Larven durch Aufzucht identifizieren konnte, ich aber an anderer Stelle in zusammenhängender Darstellung die Unterschiede der einzelnen Formen zu behandeln gedenke, so sehe ich hier von einer Beschreibung und Abbildung der vorliegenden Larve ab.

2. Perlodes dispar Rmb. (?) Ich fing in den Rindenritzen der Uferbäume $2 \sigma^{\top} \sigma^{\top}$ und am Ufer selbst 2 Larven, die zur Metamorphose schreiten wollten. Der Fund ist mir deshalb um so wertvoller, als ich auch aus anderen Gegenden Perlodes-Larven besitze, von denen die männlichen Imagines stark gekürzte Flügel haben. Nach der Färbung und Körperzeichnung zu urteilen, handelt es sich um ganz verschiedene Arten. Meines Erachtens dürfte ein vergleichendes Studium der Larven wie der Imagines am besten Klarheit in die bei manchen Arten noch dunkle Synonymik bringen.

3. Chloroperla grammatica Scop., $1 \sigma^{7}, 2$ 우, eine in allen Gegenden Deutschlands häufig auftretende Art. 
4. Is opteryx serricornis Pict., zahlreiche ơ $\sigma^{7}$ und 우. Im Westen bisher nicht beobachtet, an der Plane massenhaft auftretend.

5. Taeniopteryx seticornis Klp., 1 q ; für Deutschland aus dem Harz erwähnt.

6. Taeniopteryx risi Mort., $1 \sigma^{7}$ und 19 in Kopulation gefangen. Diese Art war in Deutschland bisher nur aus gebirgigen Gegenden bekannt (Rheinprovinz, Westfalen und Schwarzwald); sie hält sich also auch in der Ebene an langsam fliefsenden Gewässern auf.

7. Nemura variegata Oliv., mehrere $\sigma^{7} \sigma^{7}$ und 우; eine überall häufige Art.

8. Nemurella pictetii Klp., $\sigma^{7} \sigma^{7}$ und 우. Nach Mitteilung von Dr. Mertens auch an andern langsam fliefsenden Gewässern der brandenburgischen Ebene vorkommend.

Die Tatsache, dafs ich in wenigen Stunden an einer Stelle schon 8 verschiedene Arten auffinden konnte, lälst es als sicher erscheinen, dafs diese Zahl sich bei weiteren Nachforschungen noch erheblich vermehren wird, zumal wenn man berücksichtigt, dals um diese Jahreszeit für viele Arten die Flugzeit längst vorüber war. Die Plecopterenfauna des norddeutschen Flachlandes ist bisher noch fast gar nicht untersucht worden, und es würde für den Entomologen eine dankbare Aufgabe sein, sich einmal eingehender mit ihr zu beschäftigen. Möge dieser kleine Bericht, der nur einen ersten Versuch darstellt, zu weiterer eifriger Sammlung anregen. 


\section{$2 \mathrm{BHL}$ Biodiversity Heritage Library}

Schoenemund, E . 1922. "Plecopteren aus der Umgegend von Brandenburg." Deutsche entomologische Zeitschrift 1922(1), 175-176. https://doi.org/10.1002/mmnd.48019220118.

View This Item Online: https://www.biodiversitylibrary.org/item/103380

DOI: https://doi.org/10.1002/mmnd.48019220118

Permalink: https://www.biodiversitylibrary.org/partpdf/236290

\section{Holding Institution}

Harvard University, Museum of Comparative Zoology, Ernst Mayr Library

\section{Sponsored by}

Biodiversity Heritage Library

\section{Copyright \& Reuse}

Copyright Status: Public domain. The BHL considers that this work is no longer under copyright protection.

This document was created from content at the Biodiversity Heritage Library, the world's largest open access digital library for biodiversity literature and archives. Visit BHL at https://www.biodiversitylibrary.org. 